\title{
TRABALHO INFANTIL NA INDÚSTRIA DE SEMI-JÓIAS E SUAS REPERCUSSÕES NOS PROCESSOS DE ESCOLARIZAÇÃO
}

Prof. Dr. Luiz Bezerra Neto (Departamento de Educação, UFSCAR) lbezerra@ufscar.br

\author{
Prof. Dr. Eduardo Pinto e Silva \\ (Departamento de Educação, UFSCAR) \\ dups@ig.com.br
}

\begin{abstract}
Prof. Dra. Maria Cristina dos Santos Bezerra Universidade Federal do Sergipe lbezerra@terra.com.br
\end{abstract}

Tammy Ticiane Locali tammylocali@hotmail.com

\section{RESUMO:}

Este texto visa discutir o problema do trabalho infantil no setor de semi-jóias no município de Limeira. Parte-se do princípio de que esta é sempre uma questão controversa, sobretudo quando envolve pessoas com uma idade inferior àquela que a sociedade determina como sendo a maioridade, dado que a transição de infância para adolescência e desta para a idade adulta muda de acordo com a sociedade em que a pessoa está inserida. A passagem da adolescência ou juventude para a idade adulta depende, via de regra, das necessidades de ingresso no mercado de trabalho ou das lutas e conquistas de cada sociedade. Nas sociedades mais desenvolvidas a educação tem servido para retardar a entrada no mercado de trabalho. Nas menos desenvolvidas, sobretudo as sociedades que tem por base a agricultura, esse ingresso tem se dado muito mais cedo. Nas sociedades capitalistas mais pobres a necessidade da força de trabalho aliada a ausência de um projeto educacional em condições de atender a todas as crianças tem levado as crianças ainda muito cedo para a roça ou para o trabalho doméstico em condições, quase sempre, de super-exploração dessa força de trabalho sem a necessária formação para tal. Limeira-SP tem se destacado como grande produtora de semi-jóias e essa realidade tem trazido uma série de impactos sobre as configurações trabalhistas, tal como a flexibilização das relações de trabalho, a terceirização e a conseqüente precarização da força produtiva. Nesse sentido, verifica-se aspectos preocupantes da relação entre escola e trabalho. Este influencia o desempenho pessoal dos alunos, os índices de repetência, a realização dos deveres de casa e o tempo de dedicação aos estudos em casa. Parte-se do princípio de que criança que trabalha não estuda bem e não brinca. A pesquisa que aqui se apresenta é de natureza qualitativa. A análise qualitativa dos dados está sendo realizada a partir de uma abordagem interdisciplinar, incluindo, sobretudo, os referenciais da Sociologia do Trabalho, Sociologia da Educação, História da Educação e da Psicologia Organizacional, Social e do Trabalho.

Palavras-chave: Reestruturação produtiva; Trabalho Infantil; Educação 


\title{
CHILD LABOR IN THE INDUSTRY OF SEMI-JEWELS AND EFFECTS IN PROCESSES OF SCHOOLING
}

\begin{abstract}
:
This paper aims to discuss the problem of child labor in the sector of semi-jewels in the city of Limeira. It is assumed that this is always a controversial issue, especially when it involves people with an age lower than that which the company determines to be the majority, since the transition from childhood to adolescence and adulthood for the changes according to the society in which the person is inserted. The passage of adolescence or youth to adulthood depends, usually, needs to enter the labor market or the struggles and achievements of each company. In more developed societies education has served to delay the entry into the labor market. In less developed, especially the companies that is based on agriculture, this ticket has been given much earlier. In capitalist societies the poor need most of the workforce combined with lack of an education project in a position to meet all children has led the children still too early for the garden or domestic work in conditions, almost always, the super - exploitation of the workforce without the necessary training to do so. Limeira-SP is an important producer of semi-jewels and this situation has brought a number of impacts on the labor settings, such as the easing of relations, outsourcing and the consequent impoverishment of the productive force. Accordingly, there are worrying aspects of the relationship between school and work. This influences the personal performance of students, the rates of repetition, the performance of the duties of home and the time of dedication to their studies at home. It is assumed that children who work and not studying and not playing. The research that is presented here is qualitative in nature. The qualitative analysis of the data is being made from an interdisciplinary approach, in particular, the references of the Sociology of Work, Sociology of Education, History of Education and Organizational Psychology, Social and Labor.
\end{abstract}

Keywords: Productive restructuring; Child Labor, Education

\section{Introdução}

Este texto visa discutir o problema do trabalho infantil no setor de semi-jóias no município de Limeira, passando pela discussão do trabalho como função educativa, tal qual propunham os educadores socialistas do início do século XX, bem como as propostas de educação pelo trabalho presentes no Movimento dos Trabalhadores Rurais Sem Terra.

Para atingir estes objetivos discutimos as relações de trabalho no contexto da reestruturação produtiva, caracterizado pela flexibilização e precarização social e do trabalho e as implicações das mudanças nas condições objetivas e materiais de vida e de trabalho vivenciadas pelos trabalhadores da indústria de semi-jóias de Limeira, Estado de São Paulo, situando no âmbito de uma discussão mais ampla sobre o desenvolvimento do trabalho na sociedade capitalista.

A pesquisa ora se desenvolve e que deu origem a este texto é qualitativa, entretanto, a coleta quantitativa de dados tem se mostrado necessário, superando a dicotomia quantitativo-qualitativo, ou seja, compreende-se que o uso de um instrumental metodológico de pesquisa diverso permite a melhor apreensão da complexidade da totalidade concreta, assim como ressalta-se a pertinência do enfoque interdisciplinar nas 
pesquisas que tomam como objeto as distintas facetas do processo de reestruturação produtiva. Nesse sentido, a análise qualitativa dos dados está sendo realizada a partir de uma abordagem interdisciplinar, incluindo, sobretudo, os referenciais da Sociologia do Trabalho, Sociologia da Educação, História da Educação e da Psicologia Organizacional, Social e do Trabalho. Essa abordagem tem nos permitido situar no tempo e no espaço aspectos relevantes do desenvolvimento do trabalho na sociedade capitalista na qual essas "novas" realidades se inserem, buscando retirar do processo mais amplo a especificidade do trabalho infantil no setor de semi-jóias em Limeira.

As escolas participantes do projeto foram selecionadas de duas formas: a primeira determinada pela aceitação da escola em participar da atividade, permitir a entrada dos pesquisadores para a conversa inicial com as crianças, já que a escola é a intermediária entre os pesquisadores e os alunos e, em segundo lugar, pela localização, em áreas periféricas da cidade e de maior incidência de trabalho infantil. A escola é importante parceira nesta pesquisa, pois disponibiliza dados de acompanhamento da aprendizagem dos alunos via arquivo escolar. Esse material nos permite conhecer o nível de aprendizagem em que se encontram as crianças envolvidas com a produção de semi-jóias e estabelecer uma comparação com as que não estão.

Ao iniciarmos a discussão sobre a problemática do trabalho nos deparamos sempre com uma questão controversa, sobretudo quando o trabalho envolve pessoas com uma idade inferior àquela que a sociedade determina como sendo a maioridade, dado que a idade em que se supera a condição de infância e de adolescência, no sentido da condição adulta, muda de acordo com a sociedade, classe social, cultura e período histórico em que se está inserido.

A passagem da adolescência ou juventude para a idade adulta depende, via de regra, das necessidades de ingresso no mercado de trabalho ou das lutas e conquistas de cada sociedade, com vistas a melhorias na qualidade de vida de seu povo, bem como do desenvolvimento tecnológico alcançado por essa sociedade.

É claro que não se pode discutir o problema do ingresso no mercado de trabalho descolado da questão educativa, dado que a partir do século $\mathrm{XX}$, a luta por educação passou a ser uma constante em praticamente todas as sociedades ocidentais.

Nos países mais desenvolvidos, a educação tem servido para retardar a entrada dos jovens no mercado de trabalho. Nos menos desenvolvidos, sobretudo as sociedades que tem por base a agricultura, esse ingresso tem se dado muito mais cedo, dada a necessidade de mão de obra e o baixo custo desta força de trabalho.

Nas sociedades capitalistas periféricas, mais pobres, a necessidade da força de trabalho, aliada a ausência de um projeto educacional em condições de atender a todos os cidadãos, têm levado as crianças ainda muito cedo para o trabalho, tanto na roça como nas casas de famílias com maior poder aquisitivo, para a execução do trabalho doméstico em condições, quase sempre, de super-exploração dessa força de trabalho e, em muitos casos, sem a necessária formação para tal.

No município de Limeira as crianças tem trabalhado tanto no setor de semi-jóias, nos trabalhos de solda, cravação e montagem, como também nos trabalhos domésticos, momentos nos quais liberam as mães para que estas se dediquem ao trabalho do referido setor, no interior de suas casas, como demonstraremos mais adiante.

É óbvio que a formação para o trabalho, não necessariamente é obtida na escola, dado que a escola não serve somente para formar profissionais pois, como nos alerta Pistrak, em seus fundamentos da escola do trabalho, é preciso reconhecer, que "a escola sempre foi uma arma nas mãos das classes dirigentes. Mas estas não tinham nenhum interesse em revelar o caráter de classe das escolas" (PISTRAK, 2005, p.30), fazendo com 
que setores ligados, inclusive a movimentos sociais, acreditassem na possibilidade da educação pensada a partir de uma relação de neutralidade.

Nesse sentido, é preciso compreender o papel da educação e a importância que esta tem, sobretudo a partir da concepção de classe embutida em seus pressupostos, dado que segundo Pistrak (2005, p. 30), "a revolução e a escola devem agir paralelamente, porque a escola é a arma ideológica da revolução", embora, devamos ter clareza que a educação, de forma nenhuma pode ser revolucionária se não estiver calcada na realidade concreta dos sujeitos que dela participa, embasados numa teoria revolucionária e sob a orientação de um método revolucionário, no caso, o materialismo histórico. Caso contrário, correríamos o risco de cair num idealismo absoluto, pois, passaríamos a acreditar que basta transformar os homens a partir de sua subjetividade para transformarmos a sociedade.

Não podemos deixar de reconhecer, a importância da escola no processo de formação do homem, dado que, de acordo com Pistrak (2005), no processo de luta revolucionária devemos observar que uma das bases da escola do trabalho deve ser a sua relação com a realidade atual.

Quando analisamos as propostas de educação do Movimento dos Trabalhadores Rurais Sem Terra (MST), percebemos que eles chamam a atenção para a auto-organização dos alunos, outro fator considerado muito importante por Pistrak, dado que essa autoorganização contribuiria fundamentalmente para a formação de cidadãos livres e autônomos.

Seguindo este raciocínio, os educadores do MST, tem afirmado que a função das escolas organizadas nos acampamentos e assentamentos do movimento deve ser a de ajudar os trabalhadores a se descobrirem como explorados e, após a tomada de consciência, através de sua ação, eliminar esse processo de exploração.

Nesse sentido, no processo de percepção da exploração o movimento considera importante para os estudantes relembrar e comemorar as datas consideradas importantes pela classe trabalhadora e pela comunidade local. Sendo assim, uma vez que a educação é centrada no estudante, os educandos devem se auto-organizarem para celebrar esses momentos.

Considerando-se esse modelo de escola, o movimento defende que ao professor deve ser atribuído o papel de criar condições para que os alunos tomem decisões cada vez mais acertadas e coerentes com a vida do assentamento em que ele está inserido, bem como os princípios educativos e éticos do MST. Considerando essas características da escola e o trabalho do professor, esse tem necessariamente que ser alguém engajado ou comprometido com o movimento; caso contrário, a educação não atingirá seus objetivos junto ao educando.

O trabalho educativo do MST tem ganhado importância à medida que vem buscando dar respostas à ausência do Estado no campo. Além disso, este movimento tem procurado implementar uma nova forma de gerenciamento da escola pública, ao propor que o Estado apenas cuide de sua manutenção e financiamento, deixando a cargo da comunidade, através da participação de pais, alunos e professores a responsabilidade por sua organização.

Nesse sentido, o conteúdo trabalhado deve partir da realidade do aluno, tendo em vista a luta pela construção de uma sociedade socialista, como prega seus dirigentes. Já com relação à questão metodológica, procuram aproveitar tudo que imaginam ter de bom nos vários pensadores que o MST entende ter contribuído com a luta da classe operária, rumo à formação do homem integral.

Nesse sentido, embora o movimento afirme que sua pedagogia é revolucionária, é preciso deixar claro que ela não se encaixa numa pedagogia marxista. É preciso, por outro lado, reconhecer que o trabalho na pedagogia marxista deve ser compreendido como toda a Revista HISTEDBR On-line, Campinas, n. Especial, p.264-284, mai.2009 - ISSN: 1676-2584 267 
pedagogia marxiana deve ser entendida, ou seja, como uma teoria de pedagogia social, ligada ao desenvolvimento dos fenômenos sociais.

Se partirmos do princípio supracitado, poderemos inferir que deveremos concordar com Pistrak, (2005, p. 24) quando este afirma que "não pode haver teoria revolucionária sem prática revolucionária, [e que] portanto, é preciso pensar o trabalho como uma prática educativa revolucionária". É preciso compreender também que o Movimento entende que o marxismo não tem o monopólio das práticas revolucionárias.

A busca de uma educação de qualidade, sobretudo para os jovens do meio rural, já é antiga, visto que já nas décadas de 1920 e 1930 o movimento denominado de ruralismo pedagógico desencadeara luta nesta direção.

Para os ruralistas, a educação era uma necessidade da população brasileira que habitava na área rural e deveria se adequar às necessidades destes e da demanda nacional. Assim, para alguns autores, como Pastor, o problema da educação rural poderia ser resolvido facilmente, desde que se colocasse um impedimento ao trabalho pelos analfabetos pois, como na cidade, esse critério e a necessidade do trabalho justificaria a corrida da população rural pela educação.

Ele entendia que bastaria exigir do roceiro, para ingresso no trabalho, uma certa escolaridade, para que esse fosse obrigado a ingressar na escola, pois o analfabetismo, segundo sua concepção, ocorria em grande medida pela falta de estímulos por parte das autoridades à educação rural. É interessante notar que, para esses autores, a questão econômica que fazia com que os pais fossem obrigados a colocar seus filhos para trabalhar desde cedo no sitio, não aparecia como problema, assim como não aparecia como problemático o fato de as escolas rurais se localizarem a vários quilômetros das casas das crianças, forçando-as a andar durante horas para chegar às mesmas (BEZERRA NETO/2003 p. 27-28).

Através de sua proposta pedagógica, os ruralistas pretendiam desenvolver o trabalho educativo e promover a equidade social, sem que o trabalhador rural saísse do campo em busca de melhores condições de vida. Nesse sentido, a educação deveria substituir as disciplinas não ligadas com a língua/história materna brasileira pelas atividades ligadas às técnicas rurais, novas formas de compreensão do trabalho, entre outros elementos que serviriam de incentivo à procura da educação pela população que, até então, estava encerrada em técnicas precárias e arcaicas e não viam na educação nenhuma necessidade.

Ligando a educação ao trabalho, Carneiro Leão defendia um modelo de ruralismo pedagógico tal como encontrado em países que colocavam a educação do camponês juntamente com os projetos de desenvolvimento e nacionalismo político, econômico, cultural e social, como por exemplo a Dinamarca e a França. Porém, ele não compreendia que o desenvolvimento alcançado pela Dinamarca se dava mais pela equidade de distribuição de renda do que pelo investimento na educação rural.

Ao relacionar o trabalho à formação, Carneiro Leão costumava citar o Chile, país que apresentava um alto investimento nos modelos educacionais compostos por vários itens como: Escolas Elementares Completas (7-13 anos), Cursos Vocacionais Rurais (artes, ofício, industria e técnicas que melhorassem a vida doméstica como forma de incentivar o uso adequado dos recursos naturais), Missões Ambulantes (educação de jovens e adultos no local do trabalho, dando-lhes condições necessárias para converter o trabalho individual em cooperativas de trabalho) e Escolas Normais Rurais (diversos tipos de mestres voltados ao meio rural). A educação nesse contexto atendia a uma nova forma de trabalho, isto é, a aproximação solidária entre os indivíduos e a idéia de cooperação, como podemos perceber através da Escola Rural de Butantã/SP e de Juazeiro do Norte/CE. 
Mesmo acreditando que a educação era a base redentora da humanidade e que esta dirigiria o progresso do país e que cabia ao professor, assumindo o papel de representante do Estado, contribuir para a melhoria das condições de vida, tanto no meio rural quanto no meio urbano, os ruralistas tinham consciência de que os professores rurais percebiam os menores salários, contribuindo para aumentar o preconceito deste com relação ao meio rural, fazendo com que este trabalhasse no campo somente até conseguir melhores condições de trabalho na cidade.

Apesar do ruralismo pedagógico, na década de 50 o processo de industrialização ganhou vulto, contribuindo para o êxodo rural e facilitando o acesso a escola, pois esta era a exigência da industria. Para Romanelli, a educação na zona rural não se fazia necessária, pois utilizava-se técnicas arcaicas e com o processo de urbanização/industrialização procurava-se as escolas como forma de adequar-se aos critérios de trabalho, ou nas próprias palavras da autora:

Se a população se concentrava na zona rural e as técnicas de cultivo não exigiam nenhuma preparação, nem mesmo a alfabetização, está claro que, para esta população camponesa, a escola não tinha qualquer interesse. Enquanto as classes médias e operárias urbanas procuravam a escola, porque dela precisavam para, de um lado, ascender na escola social e, de outro, obter um mínimo de condições para consecução de emprego nas fábricas, para a grande massa composta de populações de trabalhadoras da zona rural, a escola não oferecia qualquer motivação. Essa foi a razão pela qual o índice de analfabetismo no período foi bastante alto e as reivindicações escolares das classes emergentes puderam ser, de alguma forma, atendidas (ROMANELLI/1990, p.45).

Já na década de 1970, o êxodo rural foi provocado pelo aumento da mecanização do trabalho no campo, tornando os trabalhadores dispensáveis e a conseqüente busca de melhores condições nas grandes cidades, embora essas pouco se alterassem. A educação rural pouco se altera também.

Na década seguinte, surge o Movimento dos trabalhadores rurais sem terra, cujo projeto de sociedade inclui uma reforma agrária baseada nos princípios da igualdade e do socialismo defendendo o trabalho para todos, distribuição de renda justa e igualitária, produção alimentar farta e saudável para toda a população, obtendo assim, justiça social e igualdade de direitos a todos os cidadãos. Segundo o Movimento, isto seria possível através da difusão dos conceitos humanistas e socialistas como forma de eliminar todos os tipos de preconceito, criando condições objetivas que garantam a recuperação dos recursos naturais para propiciar um desenvolvimento sustentável e implementação da agroindústria como forma de progresso nacional.

Por isso, os dirigentes do MST têm reivindicado do Estado que tenhamos uma escola pública do meio rural, pensada e organizada para o trabalho no campo, dando a mesma ênfase para o trabalho manual e o trabalho intelectual, rompendo assim com a dicotomia social do trabalho intelectual para uma classe e o trabalho braçal para outra. $\mathrm{O}$ MST entende, portanto, que partindo da prática produtiva para a educacional, estariam fazendo uma relação dialética entre teoria e prática, necessária para o progresso econômico e social do país (BEZERRA NETO/2003 p.150).

Seguindo este raciocínio, Ilma Ferreira Machado levanta as seguintes assertivas:

Parece procedente o MST se perguntar se suas escolas estão se "materializando" conforme seus princípios educativos e pedagógicos, se na vinculação com o poder público municipal as escolas estão se 
materializando um pouco dentro da lógica oficial de ensino - antagônica aos propósitos educativos do MST, e de que modo tem se efetivado a relação entre escola e trabalho, tão cara ao Movimento por seu papel de articulação de novas práticas sociais, pautadas no modo de vida coletivo. Resumindo: é fundamental no contexto das adversidades de uma sociedade capitalista pensar sobre a materialidade que a escola assume, como forma de avaliar a materialidade do próprio projeto político e social do MST, e de depreender dessa realidade contraditória e conflitante as possibilidades de impulsão de uma outra materialidade de escola, mais próxima da pretendida (MACHADO/2003 p.36).

Estes objetivos serviram para a elaboração dos dez princípios norteadores do projeto Escola do Campo, que reproduzimos a seguir: 1- Qualidade Social da Educação; 2Inserção num contexto global; 3- Educação voltada para a valorização da cultura e do trabalho no campo; 4- Democratização do acesso ao conhecimento; 5- Gestão Democrática; 6- Espaços e tempos alternativos de educação; 7- Construção de um novo homem a partir do resgate de sua identidade; 8- Resistência e luta do homem do campo; 9Integração e Interação com o meio ambiente e conscientização ecológica e 10- Concepção de que a história é construída pelas lutas sociais.

Nesse sentido, acredita-se que

O que movimenta a escola é o compromisso, o envolvimento, a coletividade, a organicidade, os vínculos, o respeito à diversidade e o trabalho como princípio educativo. Podemos dizer que a nossa escola é lugar de luta, espaço para a prática da liberdade e para a construção do conhecimento científico profundo. (CARAVIERI)

O MST é o mais incisivo protagonista de um discurso que clama por uma educação diferenciada para o campo. Sua atuação política envolve um conjunto amplo de entidades, tal como se deduz de um documento resultante do Seminário Nacional Por uma Educação do Campo, realizado no ano de 2002 com o objetivo de oferecer subsídios ao Governo do PT. Tal documento, denominado Por Uma Educação do Campo: Declaração 2002, teve entre os seus mentores Roseli Salete Caldart, pedagoga do MST. A reivindicação fundamental, ao longo do texto, é por uma educação do campo, justificada em algo entendido como fato natural, incontestável e resistente ao movimento histórico. Neste texto Caldart afirma que

Os povos do campo têm uma raiz cultural própria, um jeito de viver e de trabalhar, distinta do mundo urbano, e que inclui diferentes maneiras de ver e de se relacionar com o tempo, o espaço, o meio ambiente, bem como de viver e de organizar a família, a comunidade, o trabalho e a educação. Nos processos que produzem sua existência vão também se produzindo como seres humanos. (CALDART: 2002, p. 16).

O desenvolvimento dessa compreensão é relatado no décimo terceiro caderno de educação do MST, no artigo "Nossa luta é a nossa escola: a educação das crianças nos acampamentos $e$ assentamentos", que alerta que inicialmente a escola era tida como um atraso para a luta pela terra, mas que com o passar do tempo, a escola passou a ser a primeira reivindicação dos assentamentos e acampamentos em todo o país.

O Movimento afirma ainda que as resistências também eram explicadas pelo modelo descolado da realidade do campo que os trabalhadores rurais conheciam e, desse 
modo, instaurou-se as diferentes concepções que a escola do e no campo compreenderia dentro do projeto maior da luta pela conquista da terra. Estas discussões encerraram um documento básico em que foram dispostas as linhas políticas e orientações para a implementação do projeto das escolas, elaborado em 1991.

O oitavo boletim do MST sobre educação, publicado em 2001, propõe que a presença da comunidade na escola sirva para acompanhar o processo de aprendizagem das crianças e adolescentes sem terra, como também o resgate das raízes camponesas, desenvolvendo hábitos e valorização destes aspectos culturais. Ainda neste documento, o movimento chama a atenção para a coletividade das ações, as tomadas de decisões e os resultados obtidos, de forma que os indivíduos devem organizar-se e agir coletivamente. Assim, assevera que a gestão coletiva é uma estrutura orgânica que deve contemplar os sujeitos sociais que estão inseridos na comunidade que envolve tempos diferentes e conjuntos de discussão, formação e tomada de decisão.

É obvio que muitas formas de trabalho podem prescindir de uma formação específica, assim como o trabalho pode conter somente a faceta da exploração, sem nenhuma relação com a formação do indivíduo.

Neste sentido, julgamos relevante a discussão também sobre o trabalho e estudo na infância, ou mais precisamente, sobre o trabalho infantil na indústria de semi-jóias e as implicações nos processos de escolarização de alunos de escolas públicas da periferia da cidade de Limeira-SP.

Limeira está localizada na região industrial de Campinas/SP a $154 \mathrm{Km}$ da capital. É servida por duas importantes rodovias, a Anhanguera e a Bandeirantes e ainda tem uma alça bem curta para a Washington Luiz. A população estimada é de 278.776 habitantes, segundo informa a pesquisa Estimativas Populacionais 2008, divulgada recentemente pelo Instituto Brasileiro de Geografia e Estatística (IBGE).

A cidade tem se destacado ultimamente como grande produtora de semi-jóias e essa nova realidade industrial tem trazido uma série de impactos sobre as configurações trabalhistas, já que traz consigo formas modernas de relações de trabalho, incluindo a flexibilização, a terceirização e a consequiente precarização da força produtiva. Na fabricação de jóias e bijuterias é predominante a utilização de trabalhos manuais. A produção das peças brutas em sua maioria fica restrita à indústria metalúrgica, com equipamentos muitas vezes tecnologicamente ultrapassados, mas economicamente viáveis. A terceirização é a tônica, principalmente nos processos de montagem, cravação, soldagem e na obtenção dos folheados por meio dos banhos de galvanoplastia (VILELA \& FERREIRA, 2008).

Ainda segundo os autores, com o desenvolvimento internacional do mercado consumidor, as indústrias do setor iniciaram um sistema de produção peculiar, adotando a terceirização de etapas importantes do processo produtivo como uma das saídas para a competitividade do mercado. Com a terceirização, os trabalhos de montagem, soldagem e cravação foram em grande medida transferidos para os domicílios, envolvendo parentes, crianças e adolescentes neste processo.

A terceirização e precarização são fenômenos globais associados à reestruturação produtiva e à redução de políticas governamentais que deixam de conferir aos trabalhadores a devida proteção do Estado. A informalidade contribui para eliminar os encargos sociais, uma vez que todos esses trabalhos são realizados sem nenhum tipo de contrato, eliminando qualquer tipo de vínculo trabalhista entre o contratante e o contratado.

Segundo o Departamento Intersindical de Estatística e Estudos Socioeconômicos (DIEESE), o crescimento do setor de serviços, dos empregos de meio expediente e de relações de trabalho precarizadas, ou ainda, de mão-de-obra flexível, facilita a entrada de crianças no mercado de trabalho. Ainda segundo o órgão, o trabalho infantil é exercido em 
todos os setores da economia, predominando naqueles em que é mais fácil burlar a lei, dado o alto grau de precarização em que se encontram as relações de trabalho. Os serviços em geral, um certo tipo de comércio e o trabalho em casa de família estão nesse caso, mas a circunstância também tem proporcionado outro tipo de emprego que não só o doméstico. No Brasil, não são encontradas crianças apenas em setores informais da economia, mas igualmente em empresas onde se encontra crianças trabalhando no lugar de adultos, como observado na pesquisa sobre o tema feito pelo DIEESE,

Diretamente relacionado a essa precariedade, provocada pela desregulamentação do mercado de trabalho, mas também pela falta de fiscalização, está o grande número de crianças de todas as idades, e em todas as cidades, que são empregadas em firmas. Esses estabelecimentos, regularmente constituídos, têm em seu corpo de funcionários crianças com menos de catorze anos, trabalhando no lugar de adultos. Não se trata de trabalho para a família, também não justificado, porém mais fácil de ser entendido, mas de serviço contratado no mercado de trabalho.

De acordo com a PNAD, em 1993, trabalhavam no Brasil 4.547.944 crianças de cinco a catorze anos, entretanto, entre estas, 1.834.026 exerciam atividades não agrícolas, ou seja, $40 \%$ das crianças entre cinco e catorze anos que trabalham no Brasil estão nas cidades, fazendo trabalho tipicamente urbano (DIEESE).

Através da pesquisa "Reestruturação produtiva, flexibilização e precarização: mudanças nas condições objetivas e materiais dos trabalhadores da indústria de semijóias e nos processos de escolarização de seus filhos" demonstramos que temos um grande contingente de famílias voltadas para o trabalho nesse setor, envolvendo pai, filhos e esposa, principal agenciadora para o trabalho de solda, cravação e montagem de semi-jóias no município de Limeira, região que se apresenta como a capital brasileira do folheado. Além disso, o trabalho infantil urbano não recebe muita atenção por parte da imprensa e pouco tem se pesquisado a respeito, o que dá a falsa idéia da sua inexistência.

Neste estudo estamos investigando o trabalho infantil na cidade relacionando com o aproveitamento escolar, predominantemente com crianças de 7 a 10 anos, que freqüentam regularmente a escola e que estão na faixa etária em que o trabalho é proibido sob qualquer forma.

O problema do trabalho infantil no setor, no município de Limeira, ganhou grande repercussão após a publicação de uma dissertação de mestrado defendida na Unimep, de Piracicaba, que denunciava a existência de 6 mil crianças entre 11 e 16 anos trabalhando no setor. "É uma realidade típica da terceirização de serviços e delicado porque envolve o orçamento doméstico. São pais que tiram o almoço da mesa e, em seguida, fazem dela o local de trabalho com a ajuda dos filhos. É um problema social também" (FERREIRA, 2005).

O trabalho infantil é uma realidade na sociedade brasileira em diferentes períodos históricos, podendo ser verificado em vários setores, regiões e conjunturas. A visibilidade maior da realidade de trabalho infantil está sob o meio rural, no qual crianças trabalham como nas atividades cotidianas de cuidar de casa e dos arredores, ou ainda, em casos de hiper exploração, na produção de carvão, corte de cana, colheita de café, plantações de sisal, olarias e tráfico de drogas.

Em relação ao trabalho infantil no município objeto desta pesquisa, vale ressaltar que Ferreira (2005) constatou a ampliação do mesmo. Tal problema constitui uma das principais frentes de combate da Organização Internacional do Trabalho (OIT). A legislação brasileira proíbe expressamente a utilização de mão-de-obra infantil mas, dado o grau de informalidade no trabalho doméstico, esta realidade em Limeira é bastante difundida, com grandes dificuldades de fiscalização por parte tanto do sindicato como dos 
órgãos de defesa dos direitos da criança e do adolescente, dado que sequer se tem um controle dos domicílios em que este trabalho ocorre.

De acordo com o Sintrajóias, a categoria é formada por cerca de $50 \mathrm{mil}$ trabalhadores formais que atuam em joalheria, bijuteria, lapidação, prataria, relojoaria e profissionais de assistência técnica. Em Limeira, são estimados 9 mil empregos formais e 12 mil informais, totalizando cerca de 21 mil trabalhadores em num total de aproximadamente 450 empresas do setor (GAZETA DE LIMEIRA, 17/02/2007).

As irregularidades na contratação da mão de obra são apontadas também pela Procuradoria Regional do Trabalho da $15^{\mathrm{a}}$ Região, para quem há a "necessidade de uma atuação conjunta para combater as diversas irregularidades constatadas no mercado de produção de jóias, bijuterias e folheados na região de Limeira" (audiência pública realizada em 22/02/07, no auditório da Procuradoria Regional do Trabalho da $15^{\text {a }}$ Região).

Além do trabalho infantil e da super exploração da força de trabalho sem a garantia de direitos trabalhistas, a Procuradoria Regional do Trabalho da $15^{\text {a }}$ Região também aponta graves problemas de meio ambiente. De acordo o Sindicato das Indústrias de Jóias (Sindjóias) existem mais de 150 empresas clandestinas que operam na cidade, sem contar as "donas de casa" que trabalham em condições precárias. Ainda de acordo com o Sindjóias é cada vez maior o número de empregados sem registro, principalmente aposentados, donas de casa e crianças que ajudam no orçamento doméstico executando todo o processo produtivo.

A precarização das relações de trabalho se amplia à medida que, além da terceirização, já se aponta para a quarteirização dos serviços, onde se concentram as maiores irregularidades no processo produtivo, pois aí é ampliada a exploração do trabalho infantil. É preciso chamar a atenção também para as condições insalubres do meio ambiente de trabalho, que incluem a manipulação de produtos tóxicos e perigosos. Por falta de fiscalização, produtos químicos são despejados indiscriminadamente nos mananciais colocando em risco a saúde de toda a população (Ferreira, 2005).

\section{A Reestruturação do Capitalismo}

A reestruturação do capitalismo relaciona-se à reestruturação do sistema financeiro mundial e nacional, à globalização, às transformações sociais, tecnológicas e culturais e à reestruturação dos mais diversos sistemas produtivos. A esfera financeira é compreendida por Chesnais (1996) como um posto avançado do movimento de mundialização do capital. De fato, a reestruturação do capitalismo se expressa na reestruturação do sistema financeiro. Esta, por sua vez, caracteriza-se como agente e objeto da primeira.

A desregulamentação, a abertura e a desintermediação dos mercados financeiros são elementos constitutivos da mundialização financeira. Estes não somente implicam em uma interpenetração dos mercados monetários e financeiros nacionais, mas também no estabelecimento da suposição de que a estes últimos restaria apenas a subordinação aos mercados mundializados (CHESNAIS, 1996).

A desregulamentação financeira é descrita por Chesnais (1996) como movimento que aboliu regulamentações e controles no que tange à fixação dos preços e ofertas de produtos e serviços bancários e que, concomitantemente, favoreceu taxas de juros muito mais móveis e taxas de câmbio extremamente voláteis. Desse modo, a desregulamentação caracteriza-se por submeter os Estados-nação à livre circulação de recursos, não raramente aumentando a instabilidade macro-econômica e afetando os mercados internacional e 
nacional de capitais. Em contrapartida, propiciam-se garantias aos bancos e ao capital privado e especulativo (MATTOSO, 1992; CHESNAIS, 1996).

Ainda de acordo com Chesnais (1996), existem continuidades e rupturas entre o setor financeiro e setor produtivo. Por um lado a explosão de movimentos financeiros atrela-se ao setor produtivo, sobretudo ao de grandes grupos empresariais (interpenetração entre capital bancário e capital industrial). Por outro, verifica-se uma taxa de crescimento de atividades financeiras maior que a das atividades do setor produtivo, diferença esta que reflete o grau de autonomia ou dinâmica própria dos mercados financeiros.

Nessas transferências de riqueza do setor produtivo para o sistema financeiro ocorrem processos de crescimento de ativos de valor fictício. A autonomia relativa do mercado financeiro, reforçada através destes processos, contribui para o caráter crescentemente volátil do capital, o que torna ainda mais vulneráveis os países periféricos e em desenvolvimento.

Assim, a reestruturação do sistema financeiro mundial propicia a solidificação de um sistema contemporâneo de finanças "liberalizadas e mundializadas", em que as "instituições dominantes" são "os mercados financeiros e organizações financeiras que neles atuam" (CHESNAIS, 1996, p.258).

A desregulamentação e demais características constitutivas da mundialização financeira são muitas vezes exaltadas por tais organizações como elementos propiciadores do "livre mercado". Para Mattoso (1996a, p.27-54), a desregulamentação relaciona-se muito mais a uma "concorrência desregulada", de efeitos sociais nefastos, do que a uma livre concorrência, de efeitos positivos ou promissores.

Segundo Segnini (1998b, p.10-14), as alterações no mercado de trabalho no contexto da reestruturação capitalista e das estratégias de racionalização via minimização de custos e ampliação de serviços competitivos, acarretaram em: desemprego, precarização, intensificação do trabalho e terceirização.

Ainda segundo Segnini (1998b, p.16), a reestruturação financeira e as demissões no setor bancário inauguraram uma nova dimensão do processo de exclusão social brasileiro, a saber, a do desemprego de trabalhadores escolarizados e qualificados. $\mathrm{O}$ desemprego, ao lado de reinserções precárias no mercado de trabalho, foram frequientemente verificados, em detrimento de um número reduzido de trajetórias ascendentes (SEGNINI, 1998b; SILVA, 2000).

A exploração da mão-de-obra infanto-juvenil é um fenômeno global. Em 2000, a OIT estimava cerca de 351 milhões de crianças entre 5 e 17 anos economicamente ativas, tendo cerca de 65\% menos de 15 anos. Dos 245 milhões, 73\% estão empregados nas piores formas de trabalho infantil: 170 milhões exercem trabalho perigoso e 8 milhões de crianças são empregadas em condições inquestionavelmente perversas de trabalho: o trabalho escravo ou forçado, a utilização de crianças em conflito armado, a prostituição, a pornografia e o tráfico de drogas, além do tráfico de crianças e de órgãos.

Os dados acima mostram que a situação de trabalho infantil é encontrada em todos os lugares do mundo. A OIT faz uma ressalva de que o trabalho em países desenvolvidos não é considerado como uma necessidade de sobrevivência, mas está mais relacionado com a capacidade de consumo pessoal, ou seja, as crianças trabalham meio período, aliando trabalho e escola, não representando prejuízo aos estudos por ser de tempo integral.

Estamos inseridos em um novo surto de universalização do capitalismo, como modo de produção e processo civilizatório. O modo capitalista de produção, em desenvolvimento de forma extensiva e intensiva, adquire outro impulso, com base em novas tecnologias, recriação da divisão internacional do trabalho, criação de novos produtos e mundialização dos mercados (IANNI, 1996). 
A globalização é um processo de amplas proporções envolvendo nações e nacionalidades, regimes políticos e projetos nacionais, grupos e classes sociais, economias e sociedades, culturas e civilizações. Simultaneamente, ocorre a reestruturação de empresas, grandes, médias e pequenas, em conformidade com as exigências da produtividade, agilidade e capacidade de inovação abertas pela ampliação dos mercados, em âmbito nacional, regional e mundial. O fordismo, como padrão de organização do trabalho e produção, passa a combinar-se com ou ser substituído pela flexibilização dos processos de trabalho e produção, um padrão mais sensível às novas exigências do mercado mundial, combinando produtividade, capacidade de inovação e competitividade. Sob todos os aspectos, a nova divisão transnacional do trabalho e produção implica outras e novas formas de organização social e técnica do trabalho, de mobilização da força de trabalho, quando se combinam trabalhadores de distintas categorias e especialidades. Manifesta-se também na questão social, sendo alteradas as condições de vida e trabalho, provocando a busca de força de trabalho barata, modificações no exercito industrial tanto ativo quanto o de reserva, formando contingentes de desempregados mais ou menos permanentes ou subclasses em esfera global.

No Brasil, como partícipe desta sociedade global, evidentemente também apresenta as características acima apontadas. Do ponto de vista da aquisição e utilização da mão-de-obra, no processo de barateamento da produção, abre mão de um tipo de força de trabalho diversa que, do ponto de vista legal ainda não é considerada como tal, ou seja, a mão de obra infantil. Dados da OIT mostram que aproximadamente 3 milhões de crianças de 5 a 15 anos de idade estão trabalhando. Entre os que tem entre 16 e 17 anos são quase 2,4 milhões de trabalhadores. Evidencia ainda que o trabalho de crianças e adolescentes não está igualmente distribuído entre as áreas urbanas e rurais, sendo que há, respectivamente, 3,2 e 2,2 milhões de crianças e jovens trabalhando em cada uma delas, ou seja, cerca de 59\% dos indivíduos, entre cinco e 17 anos que trabalham, estão na área urbana e $41 \%$ na área rural.

O trabalho infantil, tal como acima indicado, é um problema estrutural da sociedade brasileira. Embora a preocupação com o mesmo se faça presente de forma mais evidente nos discursos políticos e institucionais na atualidade, as condições sociais e econômicas no referido contexto de globalização os reedita. Segundo Hobsbawm (1995, p.391-420) há um "impressionante aumento da desigualdade social e econômica na nova era". As novas relações sociais e as novas formas de trabalho podem ser relacionadas ao surgimento, ressurgimento e/ou agravamento de tais desigualdades.

Mattoso (1996a, p.27-54) considera que a economia mundial, que inclui um "novo padrão tecnológico" e um "novo padrão industrial", relaciona-se a uma "nova ideologia evangelizadora". Assim, a dita "nova ordem internacional" é vista como favorecedora do crescimento de "comportamento predatório ou espúrio" que se caracteriza como uma "acentuação das preexistentes formas de internacionalização e multinacionalização".

Mattoso (1996a, p.27-54; 1996b) considera que há uma crescente "geração de inseguranças no mundo do trabalho". Ao realizar análises sobre o panorama econômico nacional o autor argumenta que houve uma fragilização do poder de intervenção estatal em um contexto de adaptação passiva ao receituário da globalização. Desse modo, compreende que "problemas suplementares" estão sendo colocados a um mercado de trabalho "historicamente heterogêneo, desigual e excludente". Nesse sentido, aponta para um novo que se configura como suplemento do velho.

Heloani (1996b, p.69-76) ao tratar da "mudança de paradigma no pós-fordismo", relaciona-a a emergência de uma "nova subjetividade". Os receituários das "novas formas de gestão" das empresas hipermodernas, com "base no envolvimento, na internalização das normas" e na introdução de um "novo paradigma tecnológico" se caracterizam, segundo 
Heloani (1996b, p.69-76), por uma "forma de dominação mais implícita, voltada para a modelização da percepção política e não para a repressão explícita".

A reestruturação produtiva, a reboque da reconversão capitalista (ANTUNES, 2005; 2006) e da reestruturação financeira (CHESNAIS, 1996; SEGNINI, 1998b), tal como nos assinala Kuenzer (2002, p.91-92), configuram uma "nova forma de dualidade" que objetiva as "novas relações entre educação e trabalho". Neste contexto, a exclusão se torna cada vez mais includente, ao passo que a inclusão, contrariamente, cada vez mais excludente.

Tais considerações teóricas acima indicadas e os dados do Sindjóias e do Sintrajóias a respeito das condições de trabalho da indústria de semi-jóias em Limeira, nos apontam para a necessidade de melhor evidenciá-las. O diagnóstico de tal situação e de suas implicações sobre a escolarização dos filhos dos trabalhadores é essencial para melhor compreendermos os problemas sociais estruturais e históricos do trabalho infantil e da educação nacional.

A questão da flexibilização é central no que tange às modificações institucionais que se dão nos processos de reestruturação produtiva. Do ponto de vista teórico, a flexibilização vem sendo relacionada como fenômeno ligado à precarização social, com destaque para as questões das incertezas em relação à manutenção de direitos do trabalho, do emprego e do crescimento do desemprego.

Segundo Antunes (2006), a era da informatização caracteriza-se como era da informalização e da instabilidade social no mundo do trabalho. De acordo com este autor a concentração do capital contrasta cada vez mais com a difusão da miséria e das más condições de trabalho e emprego em diversos setores nacionais e internacionais, o que é corroborado pelas pesquisas mais recentes de inúmeros autores (MÉSZAROS, 2006; VASAPOLLO, 2006; POCHMANN, 2006; MARCELINO, 2006; LIMA, 2006; WOLFF \& CAVALCANTI, 2006; NOGUEIRA, 2006; SEGNINI, 2006; NAVARRO, 2006; ALVES \& TAVARES, 2006).

Appay (1997a) aproxima flexibilidade e reestruturação produtiva aos conceitos de controle e precarização social. A flexibilidade é compreendida pela autora como peça integrante dos sistemas de legitimação da reestruturação econômica. Appay (1997b) conceitua a flexibilidade em duas vertentes complementares: flexibilidade produtiva e flexibilidade positiva. Por flexibilidade produtiva a autora compreende "a flexibilização das estruturas produtivas, das formas de organização do trabalho intra e entre empresas, da força de trabalho através do emprego e não emprego". Já a flexibilidade positiva é definida como "conjunto de processos característicos de adaptação das estruturas produtivas e institucionais, de mentalidades e de comportamentos às novas regras econômicas e políticas da concorrência internacional" (APPAY, 1997b, 167-182).

Além da conceituação de flexibilização positiva, utilizada para aproximação à noção de controle social, Appay (1997a, p.519) também conceitua precarização social. Essa é compreendida como elemento integrante, senão constitutivo, da reestruturação produtiva. Na construção de seu conceito de precarização social, a autora levanta a hipótese de uma dupla institucionalização da instabilidade social, a saber: a da precarização da proteção social e econômica.

A precarização da proteção social inclui as transformações dos sistemas legislativos ligados ao Direito do Trabalho e às situações fora do trabalho, caminhando para uma progressiva deterioração das condições contratuais de trabalho.

A precarização econômica inclui as precarizações das estruturas produtivas e salarial, através de elementos como subcontratação e desemprego de massa, elementos estes apontados pelas pesquisas mais recentes de Hirata e Guimarães (2006). 
Castel (1998) considera a precarização social como expressão do desmantelamento da sociedade salarial, alertando que, além da precariedade no trabalho, a reestruturação produtiva também cria situações de vulnerabilidade relacional. Os efeitos subjetivos e econômicos dos trabalhadores, vítimas da precarização social ou da degradação da sociedade salarial, são sintetizados através dos seguintes significantes: "desfiliação", "supranumerários", "inúteis para o mundo", "inempregáveis" "vulnerabilidade de massa" e "individualismo negativo". (CASTEL, 1998, p.521-529).

Para Castel (1998, p.521-529) a "nova questão social", sob os auspícios da dita reestruturação, edita um "neopauperismo", diante do qual alguns se voltam à obrigação do trabalho enquanto meio de viver o dia-a-dia, enquanto que outros, menos desafortunados, concretizam um problema novo: o da "possível não empregabilidade dos qualificados".

Ao abordar o caso brasileiro comparando-o ao de outros países, Hirata (1995; 2003; 2006) considera que a reconversão capitalista no Brasil não se assemelha aos cânones teóricos tradicionais. Para tal autora, o Brasil seria um país onde a transferibilidade do modelo japonês baseia-se mais em uma crença do que em uma realidade efetiva.

Segundo Leite (1996) a dinâmica industrial centrada em baixos salários, baixo desenvolvimento tecnológico e baixa qualidade dos produtos, assim como o setor marginal intrinsecamente relacionado com o setor moderno - englobando inúmeras formas de trabalho informal mal pago, trabalhos a domicílio, redes de subcontratação e mão de obra operando ilegalmente - foram considerados como caracterizadores do cenário nacional, a despeito de suspeitas de clusters difundindo empregos ou trabalhadores qualificados.

Mattoso (1995) considera que o processo de reestruturação produtiva é expressão da reestruturação econômica. Tal reestruturação é compreendida como uma ofensiva modernizante e conservadora. Nesse sentido a defesa da flexibilização do trabalho se dá em conformidade com a lógica do mercado e apóia-se na idéia de que políticas governamentais regulatórias e protetoras, implicam em um engessamento do mercado de trabalho. Para Mattoso (1995), as formas de regulação social tendem a se enfraquecer em nome da lógica do mercado.

A insegurança no mundo do trabalho se expressa de várias formas na atualidade, a saber: insegurança no mercado de trabalho, no emprego, na renda, na contratação e na representação do trabalho. Esse rol de inseguranças relaciona-se à ampliação do trabalho informal, uma vez que uma crescente massa de trabalhadores, que perde seus antigos direitos, passa a trabalhar sob novas formas de qualificação, "em relações muitas vezes precárias e não-padronizadas" (MATTOSO, 1995, p.76-77). Tais condições refletem sobre a escolarização dos filhos dos trabalhadores, de forma que a tendência é que a problemática social se intensifique.

De modo geral, as diversas postulações teóricas acima expostas são bastante preocupantes e corroboram as justificativas por nós apresentadas acerca da importância de se pesquisar os efeitos da precarização social e do trabalho domiciliar (familiar) sobre os processos de escolarização dos filhos dos trabalhadores do referido setor, ressalvando-se que estes já sofrem percalços históricos e não somente figuram na atualidade.

Através desta pesquisa percebeu-se que o trabalho infantil na cidade é uma realidade que tem influenciado no aproveitamento escolar, predominantemente entre as crianças de 7 a 10 anos, que freqüentam regularmente a escola e que estão na faixa etária em que o trabalho é proibido sob qualquer forma. Esta forma de trabalho surgiu durante o contexto da reestruturação produtiva, caracterizado pela flexibilização e precarização social e do trabalho e as implicações das mudanças nas condições objetivas e materiais de vida e de trabalho vivenciadas pelos trabalhadores da indústria de semi-jóias de Limeira, 
Estado de São Paulo, situando no âmbito de uma discussão mais ampla sobre o desenvolvimento do trabalho na sociedade capitalista.

Os processos de flexibilização e precarização social e do trabalho vivenciados pelos trabalhadores da indústria de semi-jóias do referido município, utilizando prioritariamente o trabalho familiar feminino, doméstico que envolve a mão-de-obra infantil impactam no acompanhamento dos processos de escolarização dos seus filhos, em função das mudanças nas condições objetivas e materiais de vida dos primeiros e de seu grupo familiar e em consequiência afetam a aprendizagem das crianças. Por outro lado, a situação de trabalho infantil também afeta o desempenho pessoal dos alunos, havendo impacto nos índices de repetência, na realização dos deveres de casa que são feitos à noite ou a cada dia em um horário, na maior parte das vezes por causa do trabalho, quando são realizados. Parte-se do princípio de que criança que trabalha não estuda bem, não brinca o suficiente, não se prepara para a vida.

Quando uma criança brinca, com base na percepção que tem do mundo adulto, ela retrata não apenas as cenas do cotidiano como também os sentimentos e conflitos, transformando a atividade lúdica em um momento de se tornar adulto, não de uma forma imediata, mas simbólica. Os afazeres que exercem diariamente em casa, no campo e até no comércio da própria família, não podem ser considerados como trabalho infantil exploratório. $\mathrm{O}$ conceito pode ser melhor aplicado àquelas crianças que desde cedo exercem uma atividade regular para ajudar no seu sustento e de suas famílias. Tarefas simples delegadas pelos próprios pais, como lavar a louça, arrumar a própria cama, entre outras, não podem ser consideradas como exploração da mão-de-obra infantil, mas um processo de aprendizagem. (FERREIRA, 2005, p.33).

Em Limeira este fato é muito evidente, uma vez que o trabalho informal em domicilio utiliza muitas crianças, cujo rendimento no desempenho escolar aparece como precário. De acordo com o coordenador pedagógico de uma escola participante da pesquisa, o rendimento dos alunos que trabalham em relação aos que apenas estudam, é inferior. Isso ocorre devido ao cansaço dos alunos, e o tempo disponível para estudarem, fazerem as lições em casa.

Nesse município, com o crescimento da demanda de jóias e bijuterias, empresas de pequeno e grande porte sentiram a necessidade de terceirizarem alguns setores da manufatura para alimentar o mercado consumidor que a cada dia se torna mais competitivo, tendo como objetivo fundamental a redução do custo tanto da peça quanto do processo de fabricação bem como a eliminação dos encargos sociais. Este processo atem causado a precarização das relações de produção no setor, fazendo com que muitas crianças trabalhem na informalidade para atender a demanda dessas empresas.

Com essa nova estratégia das empresas, muitos são os casos de famílias, que por meio do trabalho terceirizado, exercem parte do processo de produção, as atividades de manufatura, em suas próprias residências, o que muitas vezes acarreta a sobrecarga de trabalho, esta sendo dividida entre os familiares, inclusive as crianças, como mostra Ferreira:

O trabalho é realizado geralmente por mulheres, e/ou demais elementos da família, crianças e idosos, categorias de força de trabalho que estão provisória ou definitivamente fora do mercado de trabalho, com baixa qualificação (FERREIRA, 2005, p.31).

Para não configurar irregularidades, o trabalho infantil é apresentado à sociedade de forma mais sutil, por meio do trabalho em família. Esta situação tem se mostrado recorrente, principalmente em famílias que se vêem obrigadas a passar serviços aos filhos, 
para que assim possam angariar fundos e suprir ao menos as necessidades básicas. "Tratase de uma realidade típica da terceirização, e de difícil resolução, pois envolve o orçamento doméstico, nos quais os pais fazem da própria mesa de refeição seu local de trabalho, com o auxilio das crianças" (FERREIRA, 2005, p.32-44).

Outra questão que se faz necessária a análise, é o fato de muitas crianças estarem expostas a condições insalubres no meio de trabalho, que incluem a manutenção de produtos tóxicos, automaticamente perigosos, que são instrumentos fundamentais para manipulação e conclusão das funções destinadas a eles, demonstrado por Ferreira como:

Com essas pesquisas constatou-se a existência de trabalho infantil e que aproximadamente $20 \%$ dos estudantes da Rede estadual de ensino trabalham na manufatura de jóias e bijuterias no município, foram também constatados problemas relacionados com riscos à saúde ocupacional como, LER/DORT (FERREIRA, 2005, p.3).

Ainda de acordo com Ferreira, os problemas relacionados à saúde ocupacional desses trabalhadores terceirizados são oriundos dos processos produtivos com os trabalhos com montagem, soldagem e cravação. As empresas transferiram essas atividades para a casa dos trabalhadores, envolvendo a maioria deles e seus familiares a riscos presentes nesta atividade como: o contato com produtos químicos perigosos, ácidos, ferros elétricos, gases emanados, materiais pontiagudo, movimentos repetitivos, posturas corporais forçadas e outros (FERREIRA, 2005, p. 16). Muitas crianças que trabalham nesse setor afirmam que as mães tem problemas de vista devido ao trabalho com solda.

De cento e oitenta e três crianças entrevistadas, de oito e doze anos, setenta e três trabalham afirmaram trabalhar com semi-jóias como atividade regular e com a finalidade de angariar fundos para o próprio sustento e para completar a renda familiar. Sendo que destas, 31 trabalham com solta fria ou quente. $\mathrm{O}$ restante das crianças trabalha com montagem e cravação, sendo que muitas dessas crianças disseram "encartelar" as peças e fazerem contagens.Das crianças que trabalham com solda, é recorrente ouvir queixas como: "agüiento até machucar", "machuca às vezes", "às vezes até sangra". Muitas crianças mostraram insatisfação com o trabalho. Outras crianças até se sentem mais responsáveis por estarem trabalhando.

$\mathrm{Na}$ ânsia pela diminuição dos custos de produção ante o aumento da competição mundial, muitas empresas têm optado pela descentralização do processo de produção, uma vez que conseguia diminuir os custos. Muitas empresas acabaram distribuindo suas operações por uma vasta cadeia de pequenas empresas e trabalhadores em domicilio.

Dada a nossa forma de organização familiar muitas crianças ficam suscetíveis ao trabalho infantil, uma vez que estando em casa acabam iniciando-se no processo de produção. Em Limeira é possível perceber que o trabalho em domicilio se dá da seguinte maneira:

Distribuidores contratados pelas empresas fabricantes percorrem residências próximas às fabricas, partilhando as tarefas a serem realizadas e que compreendem, em sua maioria, operações manuais, pelas quais a remuneração oferecida é bastante reduzida. O trabalho é realizado geralmente por mulheres, e/ou demais elementos da família, crianças e idosos, categorias de força de trabalho que estão provisória ou definitivamente fora do mercado de trabalho, com baixa qualificação (FERREIRA, 2005, p.31). 
Para um pai de família seria muito mais constrangedor ter que ver sua família sem moradia, se sujeitando as situações de exposição e humilhação, além dos perigos encontrados na rua como tentativas de rapto, estupro, atropelamentos. Tendo esse cenário como fundo para uma vida degradante, o trabalho infantil acaba sendo visto, como um mérito que o menor tem, pois assim, com o seu auxilio, consegue proteger sua família.

É neste sentido, que a pesquisa sobre o trabalho infantil no setor de semi-jóias e sua influência no processo educativo deve contribuir para avançar os estudos ora realizados sobre estes tipos de atividades.

\section{BIBLIOGRAFIA:}

ALVES, Maria Aparecida, TAVARES, Maria Augusta. A dupla face da informalidade do trabalho: "autonomia" ou precarização. In: ANTUNES, Ricardo (org.). Riqueza e miséria do trabalho no Brasil. Boitempo, Parte II (As formas diferenciadas da reestruturação produtiva do capital e a nova morfologia do trabalho), p.425-444. 2006.

ANTUNES, Ricardo. A era da informatização e a época da informalização: riqueza e miséria do trabalho no Brasil. In: ANTUNES, Ricardo (org.). Riqueza e miséria do trabalho no Brasil. São Paulo: Boitempo, p.15-26, 2006a. 527p.

ANTUNES, Ricardo. Adeus ao trabalho? Ensaio sobre as metamorfoses e a centralidade do mundo do trabalho. 10. ed. São Paulo, Cortez, 2005. 199p.

ANTUNES, Ricardo. Construção e desconstrução da legislação social no Brasil. In: ANTUNES, Ricardo (org.). Riqueza e miséria do trabalho no Brasil. Boitempo, p.499-508, 2006b. 527p.

ANTUNES, Ricardo. Os sentidos do trabalho: ensaios sobre a afirmação e a negação do trabalho. 4.ed. São Paulo: Boitempo, 2001. 258p.

APPAY, Beatrice (org.). Précarisation sociale et restructurations productives. In: Précarisation sociale, travail et santé. Paris: Iresco, 1997a. cap. 10, p. 509-553.

APPAY, Beatrice. Control sociale et flexibilisation. In: Précarisation sociale, travail et santé. Paris: Iresco, 1997b. cap.3, p.167-182.

BANCO MUNDIAL. O trabalhador e o processo de integração mundial. Washington: Relatório do Banco Mundial, 1995.

BEZERRA NETO, Luiz. "Educação no MST: um encontro com o ruralismo pedagógico" In:ACERVO - Revista do Arquivo Nacional. Rio de Janeiro/RJ, v.18, número 1 - 2, Jan/Dez 2005

BEZERRA NETO, Luiz. Avanços e Retrocessos na Educação Rural no Brasil. 2003. Tese de Doutorado, Faculdade de Educação/UNICAMP (Orientador: LOMBARDI, J. C).

BEZERRA NETO, Luiz. Sem Terra Aprende e Ensina: Estudo sobre as práticas educativas do movimento dos trabalhadores rurais Campinas/SP: Editora Autores Associados, 1999. Coleção Polêmicas do Nosso Tempo $n^{\circ} 67$

BOLETIM DE EDUCAÇÃO Setor de Educação do MST nº, junho/2001 "Pedagogia do Movimento Sem Terra - Acampamento às Escolas" p.64.

Revista HISTEDBR On-line, Campinas, n. Especial, p.264-284, mai.2009 - ISSN: 1676-2584 
CADERNO DE EDUCAÇÃO Setor de Educação do MST nº "Princípios da Educação no MST".

CADERNO DE EDUCAÇÃO. n ${ }^{\circ} 13$ Edição Especial "Dossiê MST Escola: Documentose Estudos 1990-2001".

CADERNO DE EDUCAÇÃO. Pedagogia do Movimento Sem Terra São Paulo/SP: Expressão Popular, $20043^{\mathrm{a}}$ Edição.

CALDART, Roseli. Educação em Movimento: Formação de educadoras e educadores no MST. Petrópolis/RJ: Editora Vozes, 1997.

CÂNDIDO, Antônio. A estrutura da escola. IN: PEREIRA, L. \& FORACHI, M. M.; Educação e Sociedade São Paulo/SP: Companhia Editora Nacional, 1972 p.107-128.

CARAVIERI, Adriana Maria Lopes Morales. A educação do campo na EMEF(R) Professor Hermínio Pagotto. s/d Monografia apresentada no Curso de Especialização em Educação do Campo e Desenvolvimento Turma: Milton Santos Universidade Nacional de Brasília (UNB)/ Instituto de Capacitação e Pesquisa da Reforma Agrária (ITERRA).

CASTEL, Robert. As metamorfoses da questão social: uma crônica do salário. Petrópolis, RJ: Vozes, 1998.

CHESNAIS, François. A mundialização do capital. São Paulo : Xamã, 1996.

CIPOLA. Ari. O trabalho Infantil. São Paulo: Publifolha, 2001.

COLETTI, Claudinei. A trajetória política do MST: da crise da ditadura ao período neoliberal. 2005 297p. Tese de Doutorado UNICAMP/Depto de Ciências Políticas (Orientador: BOITO JR., A.).

DIEESE. O trabalho tolerado de crianças até Catorze anos. Disponível em http://www.dieese.org.br/esp/es1abr97.xml, acesso em 04/09/2008.

FERREIRA, Marcos Antonio Libardi. Estudos de Riscos à saúde do trabalhador e ao Meio Ambiente na produção de jóias e bijuterias em Limeira-SP. Piracicaba, UNIMEP, Engenharia de Produção. Dissertação de Mestrado, 2005.

FERREIRA, Marcos Antonio Libardi. Estudos de Riscos à saúde do trabalhador e ao Meio Ambiente na produção de jóias e bijuterias em Limeira-SP. Piracicaba, UNIMEP, Engenharia de Produção. Dissertação de Mestrado, 2005.

GITAHY, Leda. Redes e flexibilidade: da mudança das práticas cotidianas a uma nova trama produtiva. In: LEITE, Márcia de Paula, GITAHY (org.). Novas tramas produtivas: uma discussão teórico-metodológica. São Paulo: Senac (Série Trabalho e Sociedade), cap.10, p.187-199, 2005.

GUIMARÃES, Nadya Araújo, CARDOSO, Adalberto Moreira, COMIN, Alvaro Augusto,. Os deserdados da indústria: reestruturação produtiva e trajetórias intersetoriais de trabalhadores demitidos da indústria brasileira. In: HIRATA, Helena, GUIMARÃES, Nadya Araujo (org.). Desemprego: trajetórias, identidades, mobilizações. São Paulo: Senac (Série Trabalho e Sociedade), cap.5, p.45-90, 2006.

HARVEY, David. A condição pós-moderna: uma pesquisa sobre as origens da mudança cultural. São Paulo : Edições Loyola, 1992.

HELOANI, Jose Roberto (2003). Gestão e organização no capitalismo globalizado: história da manipulação psicológica no mundo do trabalho. São Paulo: Atlas, 240p.

Revista HISTEDBR On-line, Campinas, n. Especial, p.264-284, mai.2009 - ISSN: 1676-2584 
HELOANI, Jose Roberto. A mudança de paradigma no pós-fordismo: a nova subjetividade. Revista Interações, São Paulo, v.1, n.2, p.69-76. 1996.

HIRATA, Helena, GUIMARÃES, Nadya Araujo (org.). Desemprego: trajetórias, identidades, mobilizações. São Paulo: Senac (Série Trabalho e Sociedade), 2006.

HIRATA, Helena, HUSSON, Michel, ROLDÁN, Martha. Reestruturaciones productivas y cambios en la división sexual del empleo - Argentina, Brasil y México. Nueva Epoca, Revista de Sociologia del Trabajo, n.24, p.75-97. 1995.

HIRATA, Helena, MARUANI, Margaret (org.). As novas fronteiras da desigualdade: homens e mulheres no mercado de trabalho. São Paulo: Senac, 2003.

HIRATA, Helena. Os mundos do trabalho: convergência e diversidade num contexto de mudança de paradigmas produtivos. In: Empregabilidade e Educação: novos caminhos no mundo do trabalho. São Paulo, Educ (PUC), 1997. p.23-29.

HOBSBAWM, Eric. A era dos extremos: o breve século XX (1914-1991). São Paulo: Companhia das Letras, 1995.

IANNI, Otávio. A era do globalismo. Rio de Janeiro, Civilização Brasileira, 1996.

KUENZER, Acacia Zeneida. Exclusão includente e inclusão excludente: a nova forma de dualidade estrutural que objetiva as novas relações entre educação e trabalho. In: LOMBARDI, José Claudinei, SAVIANI, Dermeval, SANFELICE, José Luís (org.). Capitalismo, trabalho e educação. Campinas, SP: Autores Associados, Parte III (Capitalismo, Trabalho e Educação no Brasil), cap.6, p.77-95. 2002.

KURZ, Robert. O colapso da modernização: da derrocada do socialismo de caserna à crise da economia mundial. São Paulo: Paz e Terra, 1996.

LEÃO, Antônio. Carneiro. O ensino na capital do Brasil. Rio de Janeiro: Jornal do Comércio, de Rodrigues \& C. 1926.

LEÃO, Antônio. Carneiro. Sociedade rural: seus problemas e sua educação. Rio de Janeiro: s/d.

LEITE, Márcia de Paula. A qualificação reestruturada e os desafios da formação profissional. Revista Novos Estudos Cebrap, n.45, p.79-96, jul. 1996.

LEITE, Márcia de Paula. O trabalho (re)visitado: uma discussão metodológica. In: LEITE, Márcia de Paula, GITAHY (org.). Novas tramas produtivas: uma discussão teóricometodológica. São Paulo: Senac (Série Trabalho e Sociedade), cap.11, p.201-221, 2005.

MACHADO, Ilma Ferreira. A organização do trabalho pedagógico em uma escola do MST e a Perspectiva de Formação Omnilateral. 2003 328p. Tese de Doutorado UNICAMP (Orientador: FREITAS, L. C. de).

MARCELINO, Paula Regina Pereira. Honda: terceirização e precarização - a outra face do toyotismo. In: ANTUNES, Ricardo (org.). Riqueza e miséria do trabalho no Brasil. São Paulo: Boitempo, Parte II (As formas diferenciadas da reestruturação produtiva do capital e a nova morfologia do trabalho), p.93-114. 2006.

MATTOSO, Jorge Eduardo Levi, A desordem do trabalho. São Paulo: Scritta, 1995.

MATTOSO, Jorge Eduardo Levi. (org.) Emprego e concorrência desregulada: incertezas e desafios. In: Crise e Trabalho no Brasil: modernidade ou volta ao passado? São Paulo: Scritta, 1996. 
MATTOSO, Jorge Eduardo Levi. Crise, transformações produtivo-tecnológicas e trabalho: panorama visto no Brasil. Cadernos Cesit, Campinas, SP, Instituto de Economia, UNICAMP, 1992.

MÈSZAROS, István. Desemprego e precarização: um grande desafio para a esquerda. In: ANTUNES, Ricardo (org.). Riqueza e miséria do trabalho no Brasil. São Paulo: Boitempo, Parte I (A explosão do desemprego e as distintas modalidades de precarização do trabalho), p.27-44, 2006.

NAVARRO, Vera. A indústria de calçados no turbilhão da reestruturação. In: ANTUNES, Ricardo (org.). Riqueza e miséria do trabalho no Brasil. São Paulo: Boitempo, Parte II (As formas diferenciadas da reestruturação produtiva do capital e a nova morfologia do trabalho), p.387-424. 2006.

NOGUEIRA, Claudia Mazzei. A feminização do trabalho no mundo do telemarketing. In: ANTUNES, Ricardo (org.). Riqueza e miséria do trabalho no Brasil. São Paulo: Boitempo, Parte II (As formas diferenciadas da reestruturação produtiva do capital e a nova morfologia do trabalho), p.269-295. 2006.

OIT O Brasil e o trabalho infantil no início do século 21. disponível em http://www.oitbrasil.org.br/info/downloadfile.php?fileId=116http://www.oitbrasil.org.br/in fo/downloadfile.php?fileId=116 acesso em 09/09/2008.

PASTOR, R. O professor Rural. In: Revista De Educação, jul./dez. v. XXX n. 40 e 41 Secretaria da Educação e Saúde Pública: Departamento de Educação, São Paulo: 1943.

PISTRAK, Fundamentos da Escola do Trabalho, São Paulo, expressão popular, 2005.

POCHMANN, Márcio. Desempregados do Brasil. In: ANTUNES, Ricardo (org.). Riqueza e miséria do trabalho no Brasil. São Paulo: Boitempo, Parte I (A explosão do desemprego e as distintas modalidades de precarização do trabalho), p.59-73. 2006.

ROMANELLI, Otaíza de Oliveira. História da Educação no Brasil (1930/1973) Petrópolis/RJ: Editora Vozes, $199012^{a}$ Edição.

SCHWARZ, Roberto. Um livro audacioso. In: KURZ, Robert. O colapso da modernização: da derrocada do socialismo de caserna à crise da economia mundial. São Paulo: Paz e Terra, 1996. prefácio.

SEGNINI, Liliana Rolfsen Petrilli Mulher em tempo novo: mudanças tecnológicas nas relações de trabalho. Campinas, SP: Faculdade de Educação da UNICAMP, 1995. (Tese, Livre Docência - Departamento de Ciências Sociais Aplicadas à Educação).

SEGNINI, Liliana Rolfsen Petrilli. Reestruturação nos bancos no Brasil: desemprego, subcontratação e intensificação do trabalho. Campinas, SP: Faculdade de Educação da UNICAMP, 1998. (Relatório de Pesquisa - Conclusões).

SILVA, Eduardo Pinto e. Demissões (in)voluntárias e subjetividade. Campinas, SP: Faculdade de Educação da UNICAMP, Dissertação de Mestrado, 2000 (Orientador: Lilina R. P. Segnini).

SILVA, Jair Batista da. A face privada de um banco público: os experimentos flexíveis no Banco do Brasil. In: ANTUNES, Ricardo (org.). Riqueza e miséria do trabalho no Brasil. São Paulo: Boitempo, Parte II (As formas diferenciadas da reestruturação produtiva do capital e a nova morfologia do trabalho), p.207-236. 2006.

SORJ, Bila. Mudanças e continuidades no trabalho domiciliar: algumas questões metodológicas. In: LEITE, Márcia de Paula, GITAHY (org.). Novas tramas produtivas: 
uma discussão teórico-metodológica. São Paulo: Senac (Série Trabalho e Sociedade), cap.4, p.73-85, 2005.

VASAPOLLO, Lucinano. O trabalho atípico e a precariedade: elementos estratégicos determinantes do capital no paradigma pós-fordista. In: ANTUNES, Ricardo (org.). Riqueza e miséria do trabalho no Brasil. São Paulo: Boitempo, Parte I (A explosão do desemprego e as distintas modalidades de precarização do trabalho), p.45-57. 2006.

VILELA, Rodolfo Andrade de Gouveia; FERREIRA, Marcos Antonio Libardi. Nem tudo brilha na produção de jóias de Limeira-SP. Prod. vol. 18 no.1 São Paulo, 2008. http://www.scielo.br/scielo.php?script=sci_arttext\&pid=S0103-

$65132008000100014 \& \operatorname{lng}=$ en\&nrm=iso acesso 08/09/2008.

WOLFF, Simone, CAVALCANTE, Sávio. O mundo virtual e reificado das telecomunicações: o caso Sercomtel. In: ANTUNES, Ricardo (org.). Riqueza e miséria do trabalho no Brasil. São Paulo: Boitempo, Parte II (As formas diferenciadas da reestruturação produtiva do capital e a nova morfologia do trabalho), p.237-267. 2006.

Artigo recebido em: 03/11/2008

Aprovado para publicação em: 21/01/2009 